\title{
School hygiene and deworming are key protective factors for reduced transmission of soil-transmitted helminths among schoolchildren in Honduras
}

José Antonio Gabrie ${ }^{1}$, María Mercedes Rueda ${ }^{2,3}$, Maritza Canales ${ }^{2,3}$, Theresa W Gyorkos ${ }^{4}$ and Ana Lourdes Sanchez ${ }^{1 *}$

\begin{abstract}
Background: Among many neglected tropical diseases endemic in Honduras, soil-transmitted helminth (STH) infections are of particular importance. However, knowledge gaps remain in terms of risk factors involved in infection transmission. The aim of this study was to investigate risk factors associated with STH infections in schoolchildren living in rural Honduras.
\end{abstract}

Methods: A cross-sectional study was conducted among Honduran rural schoolchildren in 2011. Demographic, socio-economic, and epidemiological data were obtained through a standardized questionnaire and STH infections were determined by the Kato-Katz method. Logistic regression models accounting for school clustering were used to assess putative risk factors for infection.

Results: A total of 320 children completed the study. Prevalences for any STH and for Ascaris lumbricoides, Trichuris trichiura and hookworms were: $72.5 \%, 30.3 \%, 66.9 \%$ and $15.9 \%$, respectively. A number of risk factors were identified at the individual, household, and school level. Boys were at increased odds of infection with hookworms (OR 2.33,95\% Cl=1.23-4.42). Higher socio-economic status in the family had a protective effect against infections by $A$. lumbricoides (OR $0.80,95 \% \mathrm{Cl}=0.65-0.99$ ) and $T$. trichiura (OR $0.77,95 \% \mathrm{Cl}=0.63-0.94$ ). Low school hygiene conditions significantly increased the odds for ascariasis (OR 14.85, 95\% Cl=7.29-30.24), trichuriasis

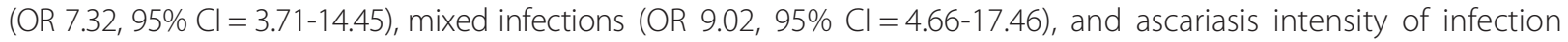
(OR 3.32, 95\% Cl=1.05 -10.52).

Children attending schools not providing deworming treatment or that had provided it only once a year were at increased odds of ascariasis (OR 10.40, 95\% Cl=4.39-24.65), hookworm (OR 2.92, 95\% Cl=1.09-7.85) and mixed infections (OR 10.57, 95\% Cl=4.53-24.66).

Conclusions: Poverty-reduction strategies will ultimately lead to sustainable control of STH infections in Honduras, but as shorter-term measures, uninterrupted bi-annual deworming treatment paired with improvements in school sanitary conditions may result in significant reductions of STH prevalence among Honduran schoolchildren.

Keywords: Soil-transmitted helminths, Geohelminths, Schoolchildren, Risk factors, Deworming, Hygiene, Cross-sectional study, Honduras

\footnotetext{
* Correspondence: ana.sanchez@brocku.ca

${ }^{1}$ Department of Health Sciences, Brock University, St. Catharines, Ontario,

Canada

Full list of author information is available at the end of the article
} 


\section{Background}

Five intestinal nematodes: Ascaris lumbricoides, Trichuris trichiura, Strongyloides stercoralis and the hookworms, Ancylostoma duodenale and Necator americanus, are collectively known as geohelminths or soil-transmitted helminths $(\mathrm{STH})$ due to their ability to survive in the environment and be transmitted through faecallycontaminated soil $[1,2]$. These geohelminthiases are among the 17 neglected tropical diseases of greatest public health concern $[3,4]$ because their health burden is particularly important in children and women of childbearing age $[5,6]$. Of the five species, $S$. stercoralis is the most overlooked due to the low diagnostic sensitivity of the methods commonly used to detect STH $[7,8]$, but disseminated infections can be fatal, particularly in immunosuppressed individuals [9].

Transmission of STH is complex as it is determined by the dynamic interaction of a multitude of factors. Social structural determinants (e.g., poverty, lack of safe water, inadequate sanitation, and inaccessible health care) in combination with favourable ecological conditions (e.g., climate, temperature, soil, altitude, and precipitation) create the overall necessary landscape in which STH infections will thrive [10]. Once these helminthiases become endemic in human settlements, a low level of education-especially health education-, lack of awareness about their importance and transmission mechanisms, as well as cultural and behavioral practices among the population, contribute to their propagation. Understanding which transmission factors are operating in a particular endemic community is key for the effective control of these parasitoses [11], but given the complex web of socio-biological determinants at play [12,13], identifying such risk factors might be challenging [14].

Although the exact number of people infected globally has yet to be determined, Pullan et al. recently estimated that a total of 1.45 billion people were infected with at least one STH species in 2010 [15]. In terms of school-age children, the WHO estimated that worldwide, in 2010, 173 million children requiring anthelmintic therapy were treated, for a global coverage of $28.2 \%$ [16]. This means that at that time there were more than 613 million schoolage children living at risk of infection on the planet.

In Latin America and the Caribbean (LAC), there are 30 STH-endemic countries and, according to the PanAmerican Health Organization (PAHO), in 2012, there were in the region 49.3 million pre-school and schoolage children at risk of infection [17]. Currently, 2.6 million of these children (including 1,840,094 school-age children) are living in Honduras (http://apps.who.int/neglected_ diseases/ntddata/sth/sth.html, accessed July 17, 2014), a lower-middle income Central American country in which $60 \%$ of the population lives in poverty (http://data. worldbank.org/country/honduras, accessed July 17, 2014).
Undernutrition is prevalent among $32 \%$ and $13.7 \%$ of Honduran children living in rural and urban settings, respectively [18]. Furthermore, recent studies have shown that STH infections have a detrimental effect on the nutritional status of Honduran schoolchildren living in impoverished rural communities [19].

With the exception of large urban centres, due to generalized deficient sanitization and hygiene, lack of clean water, and inadequate access to health care, STH transmission in Honduras occurs throughout the year and across the country. Since 2001, the Honduran government has systematically tackled the challenge of decreasing the burden of these infections [10,20]. Preventive chemotherapy through national deworming campaigns targeting school-age children (and more recently preschool children) implemented by the Ministries of Health and Education with the technical support of PAHO/WHO has been the chief intervention, as is the case in all endemic countries [4]. Due to these efforts, it is likely that STH transmission has decreased throughout Honduras, but still a national prevalence between 20 and 50\% is consistently reported [15]. In addition, recent studies have identified high-risk areas where STH endemicity is greater than $50 \%$ [20]. These data have underscored the need for epidemiological studies that help understand the transmission dynamics of these geohelminthiases in the country. The aim of the present study was to identify risk factors associated with STH transmission and infection intensity among primary schoolchildren residing in rural Honduras.

\section{Methods}

\section{Ethical considerations}

The present epidemiological study was nested within a parent study entitled "Gender and parasitic diseases: Integrating gender analysis in epidemiological research on parasitic diseases to optimize the impact of prevention and control measures" (Principal investigator, T. W. Gyorkos, McGill University, Canada). Both studies received institutional ethics approval by the three universities involved: Ethics Board of McGill University Health Centre, Montreal, QC (MUHC 10-175-PED, 23 November 2010), Ethics Board of Brock University, St. Catharines, ON (BU 10-161, 13 January 2011), and the Ethics Officer of the Master's degree program in Zoonotic and Infectious Diseases, School of Microbiology of the National Autonomous University of Honduras (OF-MEIZ-001-2011, 10 February 2011). Approval was also obtained from community leaders, school authorities, and teachers, as well as from parents and legal guardians of eligible schoolchildren. Details of the consent and assent processes can be found in a related publication based on the same study population but looking at nutritional status and STH infection [19]. After obtaining parental consent, children with STH infections 
were treated by school teachers with a single dose of albendazole (chewable tablets of $400 \mathrm{mg}$ ) provided by the Ministry of Health.

\section{Study design, geographic area, and study population}

Both the parent and the present epidemiological study were school-based, cross-sectional studies. Details on sample size calculations and field implementation have been described in a related report [19]. Briefly, the field work took place from January to March 2011, during which period nine primary schools located in rural communities within the Municipality of Catacamas, Department of Olancho, were visited: Colonia de Poncaya; Las Lomas de Poncaya; Las Parcelas; Corosito de Poncaya; Los Lirios; El Cerro del Vigía, El Hormiguero; Santa Clara; and Campamento Viejo. Schools, which had not administered deworming treatment in the last three months, were eligible for enrolment in the study. Schoolchildren specifically attending grades 3 rd to 5 th (usually aged $8-11$ years) were invited to participate because infections tend to peak at these ages $[2,5,10,19]$; they are also old enough to respond to survey questions and provide basic information. A total of 445 children constituted the eligible study population.

\section{Stool samples collection and parasite determination}

One stool sample was required from each participant to determine presence and intensity of infection using the Kato-Katz method $[21,22]$. With the help of their parents, children collected stool samples first thing in the morning the day of the interview and brought them to the research team within one hour of production. Samples were immediately placed in portable coolers to minimize parasite egg/ larvae deterioration, transported to the National University of Agriculture's laboratory in Catacamas, where they were refrigerated until smear preparation and examination for parasites the same day. The time from sample production to Kato-Katz smear preparations was approximately six hours and from the latter to microscopic examination was 30-60 minutes. Helminth eggs were identified by their characteristic features and systematically counted. Fecal egg counts were calculated for each parasite species by multiplying the numbers of eggs by a factor of 24 , thus obtaining the number of eggs per gramme of stool (epg). Infection intensities were classified as light, moderate, or heavy based on the epg calculations, according to the WHO criteria [2]. The Kato-Katz method is not ideal for Strongyloides stercoralis diagnosis, but due to the field working conditions and time constraints, no attempts were made to implement more sensitive techniques such as Koga agar plate and Baermann, as carried out by other authors [23].

\section{Children's demographic and epidemiological information} Demographic, socio-economic, and epidemiological data were collected by trained interviewers through individual, private, face-to-face interviews using a pre-tested standardized questionnaire in Spanish. Depending on the children's ability to understand and answer questions, interviews lasted between 25 and 30 minutes. Data collected included: basic demographic information, household characteristics, hygiene practices, children's chores and play activities; use of shoes or sandals; history of STH infections and deworming, as well as the level of awareness about intestinal parasites. Assessing awareness was preferred to simply measuring if children gave correct answers to independent questions, and as explained later, its assessment included if children thought they were at risk of acquiring parasites. Upon administration, questionnaires were checked for completeness and consistency by a member of the research team other than the interviewer. If missing information was detected, the interviewer was alerted and asked to retrieve it. This was possible most of the time since children were still at school after the interview.

\section{Assessment of school environment}

Schools' facilities, sanitary conditions, and deworming schedule were recorded using a standardized questionnaire which required interviewing school Principals as well as a visual inspection of the facilities by a researcher.

\section{Data management and statistical analysis}

Data from questionnaires and Kato-Katz results were entered by a researcher into Microsoft Office Excel spreadsheet 2007 (Microsoft) and verified for accuracy (compared with data in questionnaires) by a different researcher. Data were checked for errors, missing values and extreme values or outliers. Statistical analyses were carried out using Stata 13 (College Station, TX: StataCorp LP) and IBM SPSS Statistics version 20.0 (Armonk, NY: IBM Corp.). Descriptive statistics (frequency, cumulative frequency, percentages, means and standard deviations) were used to characterize the study population. Point prevalences with 95\% confidence intervals $(95 \% \mathrm{CI})$ were calculated for overall STH infections and for each STH species. Similarly, point prevalences with $95 \% \mathrm{CI}$ were calculated for monoparasitism and for mixed STH infections (i.e., infections with more than one species).

Risk factors were assessed through univariate and multivariable analyses. The defined outcomes of interest were: (i) Ascaris lumbricoides infection, (ii) Trichuris trichiura infection, (iii) hookworm infection, (iv) mixed infections, (v) moderate-to-heavy ascariasis, and (vi) moderateto-heavy trichuriasis. As previously reported [19], $S$. stercoralis was not identified among the study population, precluding any analysis for this parasite.

For the regression models, moderate and heavy infections were merged into one category and compared to light infections since the public health importance of STH 
infections is generally associated with higher worm burdens [10]. Because the vast majority $(94.1 \%)$ of hookworm infections were light; models for infection intensity were only constructed for A. lumbricoides and T. trichiura.

Based on the literature, a total of 15 variables (putative risk factors) were selected for testing their association with $\mathrm{STH}$. Of these 15 variables, three were compound variables (i.e., socio-economic status -SES-, STH awareness, and school hygienic condition); they were constructed as follows.

A household-based asset approach [24] was used to establish SES of the study participants. As recommended by the Health Nutrition and Population/Poverty thematic group of the World Bank, principal component analysis (PCA) was used to construct wealth quintiles, namely, (i) poorest, (ii) very poor, (iii) poor, (iv) less poor, and (v) least poor $[25,26]$. Briefly, PCA was calculated from household assets (electricity, TV set, and refrigerator) and house characteristics (type of floor and type of sanitary facility). The first principal component explained 54\% of the total variability. Locally weighted scatterplot smoothing (Lowess) was used to assess nonlinear relationship with the outcomes.

Determination of STH awareness was based on four criteria entailing a maximum score of five points. During the interview, children were asked if they were familiar with intestinal worms and if they thought they were at risk of getting infected with them. These questions had a dichotomous (yes/no) answer format and were assigned values of $1=$ yes and $0=$ no. Additionally, children's knowledge of STH transmission and prevention was assessed using two open-ended questions. A value of 1.5 each was assigned to these questions since they probed a higher level of understanding. Children providing at least one correct answer to these questions received the respective full marks. Lowess plots of the data were used to assess nonlinear relationship with the outcomes.

School's hygienic conditions were assessed through visual inspection of bathrooms and surrounding areas and ranked using a set of 10 hygiene indicators for a maximum score of 10 points. After Lowess plot analysis, the variable was dichotomized using a cut-off value of 6.0. Schools scoring below 6 were categorized as of lower hygienic level. The set of indicators recorded the presence or absence of desirable features such as access to water, sink, soap, functional latrine/toilet, toilet paper, cleanliness of toilet/latrine stall and surrounding areas, and odour control. Most features could be recorded with a yes/no answer and were assigned a value of 1 or 0 , respectively. Two features (i.e., type of sanitary facility and presence of a sink with water for handwashing) had three possible options, and in this case, values of $0,0.5$ and 1 were assigned to reflect absence, partial, or complete fulfillment, respectively.
Unadjusted odd ratios (OR) in the univariate analysis were calculated using logistic regression, whereas generalized estimating equations (GEE) multivariable models were used to estimate adjusted ORs. This approach accounts for the correlation among study participants attending the same school (school clustering effect). Based on likelihood-ratio (LR), a stepwise backward elimination of non-significant variables was used to find parsimonious models best predicting the outcomes, retaining those variables with $p$-values $<0.2$.

\section{Results}

\section{Study participation and population characteristics}

The details of the study participation are shown in Figure 1. Seven of the nine visited schools were enrolled in the study. The two remaining schools, Santa Clara and Los Lirios, were excluded due to recent deworming treatment or time-constraints to complete questionnaires, respectively. The final study sample consisted of 320 children.

The characteristics and parasitological findings of the study sample are presented in Table 1 . Participating children were aged 7-14 years (mean 9.76 \pm 1.4 ) and 154 (48\%) were girls. In terms of household conditions as reported by children, about $37 \%$ had partial or complete earthen floor, almost $50 \%$ had electricity, approximately $88 \%$ had either latrines or flush toilets, and $86 \%$ had piped water (usually a single faucet in the house's backyard). Most children (90\%) reported handwashing regularly and $28 \%$ acknowledged practicing habitual or occasional open defecation. More than half (58\%) of respondents recalled expelling worms in the past but, in contrast, the vast majority (97\%) did not consider themselves at risk of acquiring $\mathrm{STH}$ infections. Moreover, only 22\% of children demonstrated good understanding of STH transmission and prevention.

\section{School environment}

As per school Principals' report, five of the seven participating schools had been providing deworming treatment using a single-oral dose of $400 \mathrm{mg}$ albendazole, either twice a year (two schools) or once a year (three schools). The remaining two schools in which no deworming treatment had been administered in the last couple of years were smaller (with a combined enrolment of 86 children) and were farther away from Poncaya's health centre than the other schools. The variation in deworming frequency was attributed by Principals to the availability of medication sent by the Ministry of Health to schools across the country.

In terms of hygienic conditions, only three schools obtained scores higher than the cut-off value (6.0) and were hence considered to have a higher level of hygiene compared to the rest. This meant that less than half (42\%) of participating children were attending schools with higher levels of hygiene. At the time of the inspection, hand soap 


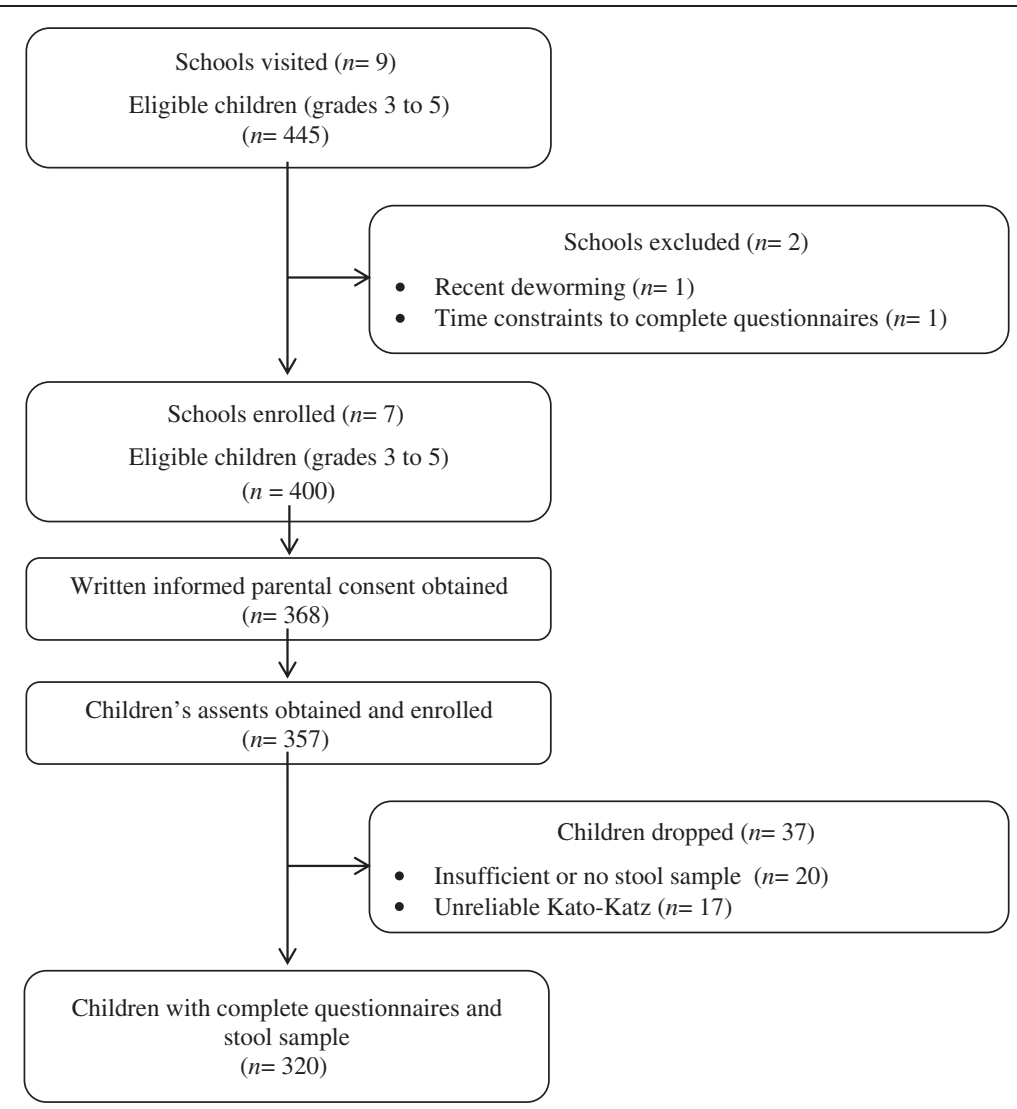

Figure 1 Flow chart detailing the study recruitment process. The investigation was conducted in 2011 and the study population comprised of children enrolled in seven schools located in rural communities of the Department of Olancho, Honduras.

was available in one school; toilet paper was available in another. According to school Principals, the school rarely provided soap and toilet paper. Most schools had functional flush toilets, although they struggled with both waste disposal in surrounding areas and odour control.

\section{Parasitological findings}

The parasitological profile of the study population has been reported elsewhere [19]. Briefly, no cases of S. stercoralis were found, and the combined prevalence of infection by any of the other helminth species was $72.5 \%$ (95\% CI = 67.3 - 77.3). Prevalences for A. lumbricoides, T. trichiura and hookworms were $30.3 \%(95 \% \mathrm{CI}=25.3-35.7), 66.9 \%$ $(95 \% \mathrm{CI}=61.4-72.0)$ and $15.9 \%(95 \% \mathrm{CI}=12.1-20.4)$, respectively (Table 1). According to egg counts, 40\%, $73 \%$ and $94 \%$ of ascariasis, trichuriasis and hookworm infections were light-intensity. More than half (53.6\%) of $A$. lumbricoides infections were of moderate intensity. Heavy-intensity infections were uncommon, representing $6.2 \%, 1.9 \%$, and $3.9 \%$ of the cases of ascariasis, trichuriasis and hookworm infections, respectively. Almost half of the children (44.4\%) had mixed infections, and $26 \%$ of them harboured all three STH species.

\section{Risk factors for STH infections}

Results of the univariate analysis are shown in Table 2. Several putative risk factors were found significantly statistically associated with infections by individual STHs (notoriously in greater number for A. lumbricoides) as well as with mixed infections. Remarkably, associations between putative risk factors and infection intensity were more frequent for moderate-to-heavy trichuriasis than for ascariasis of similar intensity.

Estimated ORs from multivariable logistic regression models of species-specific prevalences, mixed infections prevalence, and infection intensity are presented in Table 3.

The age of children was not found significantly associated with STH infection. However, as age increased by one year, the odds for ascariasis were reduced by about $20 \%$. Conversely, we observed that a one-year increase in children's age increased the odds for $T$. trichiura and hookworm infections by $15 \%$ and $20 \%$, respectively.

Sex was only found significantly associated with hookworm infection and with having mixed infections. Boys had twice the odds of both being infected by this parasite $(\mathrm{OR}=2.33,95 \% \mathrm{CI}=1.23-4.42, p=0.010)$ and harbour 
Table 1 Characteristics and parasitological findings of the study population enrolled in seven schools in rural Honduras $(n=320)$

\begin{tabular}{ll}
\hline Characteristics & $\boldsymbol{n}(\%)$ \\
\hline Age -mean (SD) & $9.76(1.4)$ \\
Girls & $154(48.1 \%)$
\end{tabular}

Household conditions

Earthen floor (complete or partial)

$(n=317)^{\mathrm{a}}$

$118(37.2 \%)$

Electricity service

$158(49.8 \%)$

Sanitary facility available

$280(87.5 \%)$

Access to piped water

$276(86.3 \%)$

\section{Practices and STH history}

Habitual or occasional open defecation

Reported regular handwashing

Walked outdoor without shoes

Performed chores outdoor

Reported expelling worms in the past

Recalled previous deworming $(n=310)^{b}$

Socio-economic status $(n=317)^{c}$

Poorest

Very poor

Poor

Less poor

Least poor

\section{Awareness and knowledge about STH}

Lowest awareness

Lower awareness

Higher awareness

Highest awareness

\section{School hygienic conditions ${ }^{d}$}

Higher level

School deworming schedule

None or once a year

Twice a year

Parasitic profile

Overall prevalence of STH infections

Ascaris lumbricoides

Trichuris trichiura

Hookworms

Mixed infections ( $n=232)$

Moderate-to-heavy infections by

Ascaris lumbricoides $(n=97)$

$91(28.4 \%)$

$287(89.7 \%)$

$163(50.9 \%)$

$62(19.4 \%)$

$186(58.1 \%)$

$275(88.7 \%)$

$75(23.7 \%)$

$58(18.3 \%)$

$61(19.2 \%)$

$60(18.9 \%)$

$63(19.9 \%)$

$89(27.8 \%)$

$137(42.8 \%)$

$22(6.9 \%)$

$72(22.5 \%)$

$135(42.2 \%)$

$246(76.9 \%)$

$74(23.1 \%)$

$232(72.5 \%)$
Table 1 Characteristics and parasitological findings of the study population enrolled in seven schools in rural Honduras $(n=320)$ (Continued)

Moderate-to-heavy infections

by Trichuris trichiura $(n=214)$

$57(26.6 \%)$

Moderate-to-heavy infections $3(5.9 \%)$

by hookworms $(n=51)$

STH: soil-transmitted helminth

${ }^{\text {a }}$ Three children did not recall type of floor at home.

${ }^{\mathrm{b}}$ Ten children did not recall receiving previous deworming treatment.

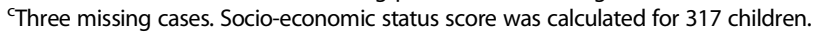

${ }^{d}$ Schools obtaining a scores $>6$ out 10 were considered having higher level

of hygiene.

multiple STH infections $(\mathrm{OR}=2.09,95 \% \mathrm{CI}=1.17-3.75$, $p=0.013)$.

Higher SES had a protective effect against A. lumbricoides $(\mathrm{OR}=0.80,95 \% \mathrm{CI}=0.65-0.99, p=0.039)$ and $T$. trichiura $(\mathrm{OR}=0.77,95 \% \mathrm{CI}=0.63-0.94, p=0.010)$. As their household SES improved by one quintile (e.g., from very poor to poor), children's odds of being infected with these two parasites decreased by $20 \%$.

Children living in households with earthen floors were at increased odds of harbouring moderate-to-heavy trichuriasis $(\mathrm{OR}=2.12,95 \% \mathrm{CI}=1.05-4.29, p=0.036)$.

Children living in households lacking toilets or latrines had increased odds of hookworm infection $(\mathrm{OR}=3.23$, 95\% CI $=1.37-7.57, p=0.007)$. They were also at increased risk of harbouring moderate-to-heavy trichuriasis although, in this case, statistical significance was only marginal ( $\mathrm{OR}=2.30,95 \% \mathrm{CI}=0.94-5.64, p=0.068)$.

When compared to children reporting regular handwashing, those describing occasional practice had about three times higher odds of harbouring infections by A. lumbricoides and $T$. trichiura, although statistical significance was only marginal ( $p=0.060$ and $p=0.067$, respectively).

Likewise, children practicing habitual or occasional open defecation had almost twice the odds of being parasitized with more than one STH species. This association too was only marginally significant $(\mathrm{OR}=1.78,95 \% \mathrm{CI}=$ $0.97-3.27, p=0.064)$.

Not wearing shoes outdoors was associated with moderate-to-heavy trichuriasis $(\mathrm{OR}=3.44,95 \% \mathrm{CI}=$ 1.73 - 6.87, $p<0.001)$.

Children who recalled expelling worms in the past had three times the odds of having moderate-to-heavy ascariasis $(\mathrm{OR}=3.00,95 \% \mathrm{CI}=1.19-7.55, p=0.020)$, and those who recalled receiving deworming treatment had reduced odds of ascariasis $(\mathrm{OR}=0.37,95 \% \mathrm{CI}=0.14$ $0.96, p=0.042$ ) and mixed infections. For the latter, though, such association did not reach statistical significance $(p=0.178)$.

Increased awareness of STH transmission played a significantly protective role against harbouring mixed infections $(\mathrm{OR}=0.75,95 \% \mathrm{CI}=0.57-0.98, p=0.036)$ 
Table 2 Univariate analysis of risk factors for STH infections in schoolchildren of rural Honduras $(n=320)$

\begin{tabular}{|c|c|c|c|c|c|c|c|c|c|c|c|c|}
\hline \multirow{3}{*}{ Variables } & \multirow{2}{*}{\multicolumn{2}{|c|}{ A. lumbricoides }} & \multirow{2}{*}{\multicolumn{2}{|c|}{ T. trichiura }} & \multirow{2}{*}{\multicolumn{2}{|c|}{ Hookworms }} & \multirow{2}{*}{\multicolumn{2}{|c|}{ Mixed infections }} & \multirow{2}{*}{\multicolumn{2}{|c|}{$\begin{array}{l}\text { A. lumbricoides } \\
\text { Mod-heavy } \\
(n=97)\end{array}$}} & \multirow{2}{*}{\multicolumn{2}{|c|}{$\begin{array}{l}\text { T. trichiura } \\
\text { Mod-heavy } \\
(n=214)\end{array}$}} \\
\hline & & & & & & & & & & & & \\
\hline & OR (95\% Cl) & $p$-value & OR (95\% Cl) & $p$-value & OR (95\% Cl) & $p$-value & OR $(95 \% \mathrm{Cl})$ & $p$-value & OR $(95 \% \mathrm{Cl})$ & $p$-value & OR (95\% Cl) & $p$-value \\
\hline$\overline{\mathrm{Age}^{\mathrm{a}}}$ & $0.94(0.78-1.12)$ & 0.488 & $1.14(0.97-1.35)$ & 0.119 & $1.23(0.99-1.52)$ & 0.053 & $1.01(0.85-1.21)$ & 0.862 & $1.02(0.78-1.34)$ & 0.867 & $0.99(0.79-1.24)$ & 0.926 \\
\hline Sex (boys vs. girls) & $1.40(0.87-2.27)$ & 0.168 & $1.06(0.66-1.69)$ & 0.815 & $2.07(1.10-3.90)$ & 0.023 & $1.64(1.02-2.65)$ & 0.041 & $1.55(0.68-3.55)$ & 0.295 & $1.02(0.55-1.87)$ & 0.959 \\
\hline $\mathrm{SES}^{\mathrm{b}}$ & $0.73(0.61-0.88)$ & 0.001 & $0.77(0.65-0.90)$ & 0.002 & $0.83(0.67-1.03)$ & 0.093 & $0.75(0.63-0.89)$ & 0.001 & $0.96(0.72-1.28)$ & 0.790 & $0.80(0.65-0.99)$ & 0.044 \\
\hline $\begin{array}{l}\text { Earthen floor at home } \\
\text { (total-partial vs. cement-tile) }\end{array}$ & $1.90(1.17-3.11)$ & 0.010 & $2.95(1.73-5.05)$ & $<0.001$ & $1.48(0.80-2.71)$ & 0.207 & $1.96(1.21-3.17)$ & 0.007 & $1.60(0.70-3.65)$ & 0.267 & $1.85(1.00-3.42)$ & 0.050 \\
\hline $\begin{array}{l}\text { Sanitary facility at home } \\
\text { (none vs. latrine-toilet) }\end{array}$ & $2.63(1.34-5.17)$ & 0.005 & $3.95(1.50-10.42)$ & 0.006 & $2.65(1.24-5.65)$ & 0.012 & $3.00(1.53-5.90)$ & 0.001 & $0.60(0.22-1.63)$ & 0.321 & $2.45(1.15-5.21)$ & 0.020 \\
\hline $\begin{array}{l}\text { Piped water at home } \\
\text { (no vs. yes) }\end{array}$ & $2.15(1.12-4.13)$ & 0.021 & $2.48(1.11-5.55)$ & 0.027 & $0.81(0.32-2.03)$ & 0.654 & $1.94(1.01-3.70)$ & 0.045 & $1.01(0.37-2.77)$ & 0.983 & $0.50(0.19-1.27)$ & 0.145 \\
\hline $\begin{array}{l}\text { Handwashing } \\
\text { (occasionally vs. regularly) }\end{array}$ & $2.08(1.00-4.33)$ & 0.050 & $3.04(1.14-8.13)$ & 0.027 & $1.19(0.47-3.06)$ & 0.711 & $1.88(0.91-3.91)$ & 0.089 & $0.73(0.24-2.22)$ & 0.582 & $1.36(0.58-3.22)$ & 0.482 \\
\hline $\begin{array}{l}\text { Open defecation } \\
\text { (occasional-habitual vs. no) }\end{array}$ & $3.11(1.86-5.20)$ & $<0.001$ & $3.03(1.66-5.54)$ & $<0.001$ & $1.99(1.07-3.70)$ & 0.030 & $3.30(1.98-5.50)$ & $<0.001$ & $0.95(0.42-2.15)$ & 0.898 & $2.04(1.10-3.81)$ & 0.024 \\
\hline $\begin{array}{l}\text { Wearing shoes outdoors } \\
\text { (no vs. yes) }\end{array}$ & $1.67(1.03-2.71)$ & 0.038 & $1.25(0.78-2.00)$ & 0.344 & $1.21(0.66-2.21)$ & 0.538 & $1.64(1.02-2.63)$ & 0.042 & $1.80(0.78-4.15)$ & 0.165 & $2.71(1.41-5.18)$ & 0.003 \\
\hline $\begin{array}{l}\text { Domestic chores } \\
\text { (outdoor vs. indoor) }\end{array}$ & $2.45(1.39-4.35)$ & 0.002 & $2.12(1.09-4.12)$ & 0.026 & $1.53(0.76-3.10)$ & 0.231 & $2.58(1.46-4.56)$ & 0.001 & $1.75(0.69-4.43)$ & 0.234 & $1.47(0.73-2.94)$ & 0.281 \\
\hline $\begin{array}{l}\text { Recalled expelling worms } \\
\text { (yes vs. no) }\end{array}$ & $1.83(1.11-3.02)$ & 0.019 & $1.46(0.91-2.34)$ & 0.113 & $1.39(0.74-2.59)$ & 0.301 & $1.73(1.06-2.82)$ & 0.028 & $2.43(1.01-5.85)$ & 0.048 & $1.53(0.80-2.91)$ & 0.195 \\
\hline $\begin{array}{l}\text { Recalled previous deworming } \\
\text { (yes vs. noc) }\end{array}$ & $0.71(0.34-1.47)$ & 0.354 & $1.57(0.76-3.21)$ & 0.219 & $0.76(0.31-1.85)$ & 0.549 & $0.78(0.38-1.63)$ & 0.513 & $1.79(0.55-5.84)$ & 0.337 & $0.88(0.32-2.42)$ & 0.807 \\
\hline STH awareness ${ }^{d}$ & $0.86(0.67-1.11)$ & 0.248 & $0.90(0.72-1.11)$ & 0.314 & $0.74(0.55-1.00)$ & 0.053 & $0.80(0.63-1.01)$ & 0.061 & $0.98(0.69-1.40)$ & 0.912 & $0.95(0.71-1.28)$ & 0.759 \\
\hline $\begin{array}{l}\text { School hygiene (lower } \\
\text { vs. higher level) }\end{array}$ & $6.37(3.46-11.73)$ & $<0.001$ & $4.75(2.88-7.84)$ & $<0.001$ & $1.05(0.57-1.93)$ & 0.874 & $4.32(2.49-7.48)$ & $<0.001$ & $2.60(0.84-8.07)$ & 0.098 & $1.27(0.64-2.51)$ & 0.491 \\
\hline $\begin{array}{l}\text { School deworming } \\
\text { (none-once vs. twice a year) }\end{array}$ & $3.50(1.71-7.17)$ & $<0.001$ & $0.81(0.46-1.43)$ & 0.480 & $3.17(1.21-8.32)$ & 0.019 & $3.89(1.90-7.96)$ & $<0.001$ & $0.99(0.26-3.79)$ & 0.989 & $5.83(1.99-17.08)$ & 0.001 \\
\hline
\end{tabular}

OR: odds ratio; Cl: confidence interval; STH: soil-transmitted helminth; SES: socio-economic status; Mod-Heavy: moderate-to-heavy infections.

${ }^{\mathrm{a}} \mathrm{Age}$ as continuous variable in years.

${ }^{\mathrm{b}} \mathrm{SES}$ quintiles calculated as described in methodology section. Three missing data $(n=317)$

${ }^{c}$ Ten children did not recall receiving previous deworming treatment.

${ }^{\mathrm{d}} \mathrm{STH}$ awareness score calculated as described in methodology section. Range $=0-5$. 
Table 3 Multivariable logistic models of STH infections using Generalized Estimating Equations to account for within-school clustering

\begin{tabular}{|c|c|c|c|c|c|c|c|c|c|c|c|c|}
\hline & $\begin{array}{l}\text { A. lumbricoides } \\
(n=307)\end{array}$ & & $\begin{array}{l}\text { T. trichiura } \\
(n=317)\end{array}$ & & $\begin{array}{l}\text { Hookworms } \\
(n=320)\end{array}$ & & $\begin{array}{l}\text { Mixed infections } \\
(n=310)\end{array}$ & & $\begin{array}{l}\text { A. lumbricoides } \\
\text { Mod-heavy } \\
(n=96)\end{array}$ & & $\begin{array}{l}\text { T. trichiura } \\
\text { Mod-heavy } \\
(n=211)\end{array}$ & \\
\hline Variables (Risk category) & OR $(95 \% \mathrm{Cl})$ & $p$-value ${ }^{a}$ & OR $(95 \% \mathrm{Cl})$ & $p$-value ${ }^{a}$ & OR $(95 \% \mathrm{Cl})$ & $p$-value ${ }^{a}$ & OR $(95 \% \mathrm{Cl})$ & $p$-value ${ }^{a}$ & OR $(95 \% \mathrm{Cl})$ & $p$-value ${ }^{a}$ & OR $(95 \% \mathrm{Cl})$ & $p$-value \\
\hline $\operatorname{Age}^{\mathrm{b}}$ & $0.84(0.67-1.05)$ & 0.120 & $1.14(0.92-1.43)$ & 0.226 & $1.21(0.96-1.53)$ & 0.107 & - & & - & & $0.85(0.65-1.09)$ & 0.206 \\
\hline Sex (Boys) & $1.64(0.90-3.00)$ & 0.106 & - & & $2.33(1.23-4.42)$ & 0.010 & $2.09(1.17-3.75)$ & 0.013 & - & & - & \\
\hline SES $\left(\right.$ Lower) ${ }^{c}$ & $0.80(0.65-0.99)$ & 0.039 & $0.77(0.63-0.94)$ & 0.010 & - & & - & & - & & - & \\
\hline $\begin{array}{l}\text { Earthen floor at home } \\
\text { (Total or partial) }\end{array}$ & - & & - & & - & & - & & $1.87(0.77-4.55)$ & 0.166 & $2.12(1.05-4.29)$ & 0.036 \\
\hline $\begin{array}{l}\text { Home sanitary facility } \\
\text { (None) }\end{array}$ & - & & - & & $3.23(1.37-7.57)$ & 0.007 & - & & - & & $2.30(0.94-5.64)$ & 0.068 \\
\hline $\begin{array}{l}\text { Handwashing } \\
\text { (Occasionally) }\end{array}$ & $2.56(0.96-6.79)$ & 0.060 & $2.70(0.93-7.81)$ & 0.067 & - & & - & & - & & - & \\
\hline $\begin{array}{l}\text { Open Defecation } \\
\text { (Habitual or occasional) }\end{array}$ & - & & - & & - & & $1.78(0.97-3.27)$ & 0.064 & - & & - & \\
\hline $\begin{array}{l}\text { Wearing shoes } \\
\text { outdoors (No) }\end{array}$ & - & & - & & - & & - & & - & & $3.44(1.73-6.87)$ & $<0.001$ \\
\hline $\begin{array}{l}\text { Recalled expelling } \\
\text { worms (Yes) }\end{array}$ & - & & - & & - & & - & & $3.00(1.19-7.55)$ & 0.020 & - & \\
\hline $\begin{array}{l}\text { Recalled deworming } \\
(Y e s)^{d}\end{array}$ & $0.37(0.14-0.96)$ & 0.042 & - & & - & & $0.55(0.23-1.31)$ & 0.178 & - & & - & \\
\hline $\begin{array}{l}\text { STH awareness } \\
\text { (Lower) }^{\mathrm{e}}\end{array}$ & - & & - & & $0.72(0.52-0.99)$ & 0.040 & $0.75(0.57-0.98)$ & 0.036 & - & & - & \\
\hline $\begin{array}{l}\text { School deworming } \\
\text { (None or only } \\
\text { once a year) }\end{array}$ & $10.40(4.39-24.65)$ & $<0.001$ & $2.08(0.97-4.45)$ & 0.067 & $2.92(1.09-7.85)$ & 0.034 & $10.57(4.53-24.66)$ & $<0.001$ & - & & $8.12(2.33-28.20)$ & 0.001 \\
\hline $\begin{array}{l}\text { School hygiene } \\
\text { (Lower level) }\end{array}$ & $14.85(7.29-30.24)$ & $<0.001$ & $7.32(3.71-14.45)$ & $<0.001$ & - & & $9.02(4.66-17.46)$ & $<0.001$ & $3.32(1.05-10.52)$ & 0.041 & - & \\
\hline \multicolumn{13}{|c|}{ 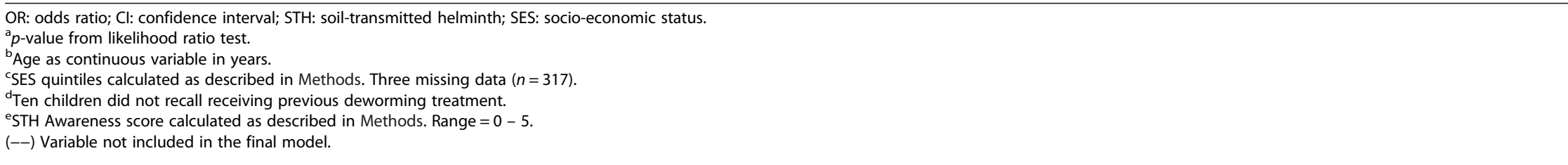 } \\
\hline
\end{tabular}


and hookworms $(\mathrm{OR}=0.72,95 \% \mathrm{CI}=0.52-0.99, p=$ 0.040 ), but not against the other two species.

The school environment was found to play an important role in STH infections. School deworming frequency was significantly inversely associated with ascariasis, hookworm infection, and multiple parasite infections. Children attending schools with absent or once-a-year deworming schedules had increased odds of being infected by A. lumbricoides $(\mathrm{OR}=10.40,95 \% \mathrm{CI}=4.39-24.65, p<0.001)$, of harbouring hookworm infections $(\mathrm{OR}=2.92,95 \% \mathrm{CI}=$ $1.09-7.85, p=0.034)$, and of harbouring mixed infections $(\mathrm{OR}=10.57,95 \% \mathrm{CI}=4.53-24.66, p<0.001)$. In contrast, the association between deworming schedule and $T$. trichiura infections was only marginally significant $(\mathrm{OR}=2.08,95 \% \mathrm{CI}=0.97-4.45, p=0.067)$.

Children in schools with absent or once-a-year deworming schedules had significantly increased odds of having moderate-to-heavy trichuriasis $(\mathrm{OR}=8.12,95 \% \mathrm{CI}=2.33$ $28.20, p<0.001$ ).

School hygienic conditions were significantly inversely associated with the prevalence of $A$. lumbricoides and T. trichiura infections as well as with the prevalence of mixed infections. Children attending schools with a lower level of hygiene had increased odds for ascariasis $(\mathrm{OR}=14.85,95 \% \mathrm{CI}=7.29-30.24, p<0.001)$, trichuriasis $(\mathrm{OR}=7.32,95 \% \mathrm{CI}=3.71-14.45, p<0.001)$ and for harboring mixed infections $(\mathrm{OR}=9.02,95 \% \mathrm{CI}=4.66-17.46$, $p<0.001$ ). Similarly, low hygienic conditions in the schools were significantly associated with higher intensity infections with $A$. lumbricoides $(\mathrm{OR}=3.32,95 \% \mathrm{CI}=1.05$ $10.52, p=0.041)$.

\section{Discussion}

Despite the ubiquitous nature of childhood soil-transmitted helminthiases in Honduras [20,27], research on this topic in the country is limited. Here we present an in-depth investigation of the risk factors playing a role in the prevalence of STH infections in Honduran children living in endemic rural communities. In the univariate analysis, a series of factors were found significantly statistically associated with STH infection, but once controlling for possible confounders and school cluster effect, the strength of association for some factors decreased. Thus, the following discussion pertains only to the risk factors included in the multivariable logistic models.

\section{Children's age}

Although it is widely known that increased age is a protective factor for both $A$. lumbricoides and T. trichiura infections [28-32] and a risk factor for hookworm infections [33-38], this was not observed in our study population. Such a finding may be due to the narrow age range of the participating children (7-14 years). In fact, our study identified a consistent trend in the protective effect of age over A. lumbricoides infection, and conversely, as a risk factor for hookworm infection. Unexpectedly, and as found by a recent study in Laos [39], we observed that as the age of children increased, the odds of having trichuriasis also increased. We could not find a plausible explanation in the literature for this finding and can only suggest assessing its validity through larger studies and/or longitudinal studies including wider population age groups. It would be also worth evaluating whether deworming treatment has any differential effect on the age distribution of reinfections.

\section{Sex of the children}

We found that the odds of having mixed infections were significantly higher in boys than in girls. Also, being a boy was significantly associated with increased prevalence of hookworm infection. However, boys in our study did not report outdoor activities or barefoot walking more frequently. Studies on hookworm infections worldwide have consistently identified higher infection prevalence in males $[34,37,38,40-43]$ but so far, it is unclear whether this finding is due to differential exposure [44], physiological factors [45,46] or a combination of both [33,47]. Future STH investigations in Honduras need to pay closer attention to sex and gender differentials and evaluate the impact of social roles and behaviours in terms of STH infection and reinfection.

\section{Family socio-economic status (SES)}

Significantly lower odds of having ascariasis and trichuriasis (but not hookworms) were found in children belonging to families in the upper SES quintiles. It has been proposed that A. lumbricoides and T. trichiura are mainly transmitted within the domestic domain whereas hookworms are transmitted in the public domain $[48,49]$. Hence, increases in family SES may have a direct effect in preventing both ascariasis and trichuriasis but not infection by hookworm. In general, our findings coincide with other studies conducted worldwide $[26,39,41,50-53]$ and show that even in communities where poverty seems to affect everyone equally, slight variations in wealth within households may be able to exert a protective effect against STH infections. Interestingly, as discussed above, the specific absence of sanitary facilities in the homes was not statistically associated with $A$. lumbricoides or $T$. trichiura. Altogether our data may suggest that beyond material possessions, a higher SES may also represent increased level of education among family members, increased hygiene practices, or perhaps both. Data on parents education or family composition was not collected by our survey and this is a gap that needs to be addressed in future investigations. 


\section{Sanitary facilities in the home}

Only $12.5 \%$ of research participants lived in households without an adequate option for feces disposal. Our findings are congruent with data from the Honduran government stating that $15.5 \%$ of rural homes are in a similar situation (http://www.ine.gob.hn/index.php/datos-y-estadisticas/ estadisticas-sociales-y-demograficas/vivienda/69-acceso-asevicios-basicos, accessed July 17, 2014). This lack of sanitary facilities increased children's risk of acquiring hookworm infections by an order of three compared to children with access to at least a latrine at home. Comparable studies in Guinea-Bissau [38], Burkina-Faso, Ghana and Mali [37] have made similar observations. An explanation proposed for these findings is that in the absence of toilets or latrines, children return regularly to the defecation site, where viable, infectious hookworm larvae remain and the children are therefore continually exposed to reinfection [54]. Linking this finding with the above-mentioned increased odds of hookworm infection in boys, it would be worthwhile investigating whether boys have more consistent behaviour patterns than girls. This was not assessed by the present study. In terms of $A$. lumbricoides or T. trichiura, unlike other studies [55-58], our data did not support a statistical association between these two species and the absence of sanitary facilities in the homes.

\section{Handwashing}

Our data show a marginal statistical significant difference between children practicing only occasional handwashing versus those reporting handwashing regularly: they had almost a three times higher odds of being infected by $A$. lumbricoides and $T$. trichiura. A large body of literature supports access to clean water and handwashing as cost-effective and important hygiene measures in preventing the spread of infectious diseases in general [59-61] and intestinal helminths in particular $[34,39,41,62,63]$. A major review carried out in 2009 by Fung and Cairncross shows that studies (most relying on self-reporting) have found disparate results when assessing the association of handwashing with the prevalence and infection intensity of $A$. lumbricoides [63]. Inconsistencies between self-reported handwashing versus actual observation have been documented by other authors [64]. Altogether these findings underscore the need for studies to use reliable, perhaps standardized indicators when characterizing hygiene-related habits and attitudes.

\section{Open defecation (OD)}

About 28\% of children acknowledged practicing either habitual or occasional OD. This figure seems excessive since only $12.5 \%$ of children reported not having at least a latrine at home. However, it is important to clarify that information in regard to actual usage or functionality of sanitary facilities at home was not collected by our survey. Therefore, it is entirely possible that not all children were able or willing to use the latrine or toilet in the home or school. Conversely, in view of the personal nature of the question, it is also possible that not all children practicing OD acknowledged such practice [65]. These inconsistencies in the data and gaps might explain why our study could not identify OD as a risk factor for STH infections. However, other similar studies were not able to demonstrate this particular association either [14,34,62].

\section{Self-reported worm expulsion and deworming history}

It was interesting to find a statistically significant association between a past history of expelling intestinal worms (likely $A$. lumbricoides adults, due to their size) and the odds of having a moderate-to-heavy infection by this parasite. It is possible that heavily infected children are regularly passing worms and are thus more likely to notice and remember; they may also have more concerns and might be more likely to report it. This finding suggests that selfreporting might be a good indicator for finding heavily infected children who merit individual attention and health care. Our study also found that a history of previous deworming as reported by children was significantly associated with a $64 \%$ reduction in the odds of having ascariasis but not the other two infections. This result is important for two reasons. Firstly, it hints to the greater effectiveness of preventive chemotherapy (PC) with single-dose albendazole against $A$. lumbricoides than for the other two STH species [66,67]. Secondly, it reveals that Honduran rural children are very familiar with deworming treatment and are able to reliably recall if deworming tablets have been provided to them at school. The latter could be used as a rapid monitoring tool for treatment uptake, which, combined with strategic prevalence studies, could provide a more complete idea of the country's situation.

\section{STH awareness}

Increasing the level of awareness about STH -how parasites are acquired, their importance, and what it means for the host to harbour them- has proved effective in preventing STH infections [68]. Accordingly, health education is suggested as a fundamental component of comprehensive STH control programs [10,69-72]. In the studied children, level of awareness showed a significant protective effect against hookworm infections probably because these tend to occur at greater frequency in older children, who in turn may have greater awareness than younger children. This explanation, however, remains speculative as our data show find a strong association between age and hookworm infection.

\section{Hygiene conditions in the schools}

A major finding from this study was that the hygiene conditions in the schools played an important role in the 
transmission of both A. lumbricoides and T. trichiura, and also in the prevalence of mixed infections. Further, independently of other factors, children enrolled in the schools with lower hygiene levels were more likely to harbour higher intensity infections by $A$. lumbricoides. There is no doubt that improvements to water, sanitation, and hygiene (WASH) contribute to a significant reduction in STH transmission [73,74] but empirical evidence of this positive association is not always demonstrated. A recent meta-analysis was just able to show that WASH access and practices at the community level were associated with reduced odds of STH infection [75]. At the school level, some cross-sectional studies have shown that poor school sanitation increased the risk for parasitic infections [76]. More recently, a cluster-randomized trial undertaken in Kenya, demonstrated that school hygiene and sanitation reduced the re-infection prevalence of $A$. lumbricoides [77]. Our study is the first in Honduras to investigate the role of school hygiene on STH transmission and our results can perhaps open the discussion for greater involvement by school teachers. School teachers have already proven to be valuable aides in STH control programs [78]. As direct lines of communication with pupils, school authorities, and parents, teachers could become instrumental advocates for cleaner, more hygienic schools thus further preventing opportunities for STH transmission [79]. Given that they spend between 5 to 6 hours a day in school, such improvements may result in significant health gains for children.

\section{School deworming schedule}

A second major finding of this study was that frequency of deworming in the schools was strongly associated with lower STH prevalence. It was also associated with lower intensity of $T$. trichiura infections. This is good news for the Honduran government as it provides evidence that current efforts are helping to achieve control targets (http://presencia.unah.edu.hn/vinculacion/articulo/ desparasitaran-a-dos-millones-de-escolares- accessed July 17, 2014). On the other hand, our study revealed that operational challenges remain, as, despite geographical proximity, not all schools had administered PC in the last couple of years. Finding that children who had not received PC had similar odds of being infected by $A$. lumbricoides and hookworms, as well as of being infected by multiple STH species than children receiving PC once a year, lends support to the decision by the Honduran Ministry of Health of increasing the frequency of PC administration, as suggested by international health governing bodies $[10,80,81]$. While it is recognized that PC alone will not eliminate STH infections $[82,83]$, administered at the appropriate frequency, it can decrease the burden and morbidity of these parasitoses [84]. Finally, the frequency of deworming in the schools showed only a marginally significant effect in $T$. trichiura prevalence, which is likely due to the low efficacy of single-dose albendazole/mebendazole against this parasite $[66,67,85]$. This might explain why this and other Honduran studies show that $T$. trichiura is becoming the predominant STH species in the country [20].

Examining the school environment by assessing both the physical sanitary conditions as well as the schools deworming practices revealed crucial information and our results lend support to WHO's Health promoting schools (HPS) initiative [86]. In terms of STH infections, greater consideration should be given to schools as either potential enablers of transmission or as crucial players in their control.

It is worth emphasizing that we did not implement techniques sensitive enough for reliable S. stercoralis detection. Although the personnel performing the KatoKatz examination were experienced and would have been able to identify helminth larvae in fecal smears, had they been present, the possibility of underdiagnosis due to the method's low sensitivity cannot be ruled out. Regrettably, there is no reliable prevalence data for $S$. stercoralis in Honduras. A national survey carried out by the Ministry of Health in 2011 also utilized the KatoKatz method. A sample of 2,554 schoolchildren enrolled in 48 schools across the nation were examined and a prevalence of $0.4 \%$ for S. stercoralis was found (while prevalences for A. lumbricoides, T. trichiura and hookworms were $22.3 \%, 34 \%$ and $0.9 \%$, respectively) [87]. In Honduras, as in many countries, S. stercoralis is rarely recognized as a public health problem [88], and future studies should strive to integrate its diagnosis.

There are some limitations to the present study. Since the study population was obtained through the parent study, which aimed to assess gender-specific risk behaviours in relation to STH prevalence (manuscript in preparation), our sample size was not calculated with our primary outcomes in mind and this may have somewhat limited the power of the study. Reporting biases might have been introduced while collecting information from participating children (e.g., household SES data; self-reporting of hygiene practices such as handwashing, OD, usage of shoes). Also, information on parents' level of education was not obtained and such data might have been important when constructing the SES variable. There are also potential limitations in terms of the diagnostic methodology utilized in this study. The time elapsed between sample production by research participants and smear preparation was approximately six hours, and as noted by other authors, some hookworm eggs and S. stercoralis larvae may have deteriorated, thus limiting diagnostic sensitivity and resulting in under-reporting [89]. However, the prevalence of hookworm infections obtained in our study was $15.9 \%$, a much higher figure than the $0.9 \%$ national prevalence 
reported in the last survey conducted by the Ministry of Health in 2011. Further, more relevant to our study, the national survey included examining 230 school children 9-11 years of age living in rural communities of Olancho, the same Department where the present study was conducted, and found a prevalence of $0 \%$ [90]. Our success in detecting hookworm eggs may be due to having stored samples under cool conditions until smear preparation. Other authors have found that hookworm eggs were best preserved by keeping samples on ice or covered with a wet tissue [91].

Finally, given that this was a cross-sectional study in a defined geographical area, our findings might not be generalizable to other ecological zones in the country.

Despite these limitations, our study also possesses important strengths, for example, a high participation rate, the representativeness of our study participants of the rural population of Honduras, [18], and the use of the Kato-Katz method, recommended by the WHO for STH epidemiological surveys. Even though the analysis of a single-stool sample by a single diagnostic method might have underestimated prevalence and/or intensity of infection [23], in light of the high prevalence obtained, this underestimation might be minimal. Other authors concur that the Kato-Katz method can yield accurate results with one day's stool collection for both A. lumbricoides and $T$. trichiura, although less so for hookworm eggs $[92,93]$. An important strength of this study stems from the fact that we utilized robust statistical methods and modelled risk factors considering plausible variables for STH transmission taking into account within-school clustering.

\section{Conclusions}

The findings presented here demonstrate that Honduras's STH control efforts are going in the right direction. They also emphasize the need for continued PC administration, uptake and monitoring across the territory, paying particular attention to remote rural communities. In addition, our data suggests that remaining vigilant of STH prevalence trends, especially for T. trichiura, would be useful for assessing PC efficacy and assuring timely detection of drug resistance.

In light of the risk factors we found associated with STH infections, our findings also support the need for an integrated approach to STH control in Honduras [51,80,94,95]; one that leads to resource optimization among different sectors to improve health outcomes [84]. An integrated approach is, in fact the country's goal, as expressed in the "National strategic plan for the prevention, attention, control, and elimination of neglected infectious diseases in Honduras, 2012-2017" (PEEDH) [87]. However, the ability to address these factors in a comprehensive and integrated manner may be compromised by the reality of Honduras as a developing country [84]. Therefore, more feasible interventions need to be considered at the moment. We propose that along with the uninterrupted bi-annual deworming treatment of both preschool-age and schoolage children, dedicated actions are taken to improve the hygienic conditions of the schools where Honduran children learn and play.

\section{Abbreviations \\ Cl: Confidence interval; EPG: Eggs per gramme (of stool); GEE: Generalized estimating equations; OR: Odds ratio; PAHO: Pan American Health Organization; PC: Preventive chemotherapy; SES: Socio-economic status; STH: Soil-transmitted helminth; UNA: Universidad Nacional de Agricultura (National University of Agriculture); UNAH: Universidad Nacional Autónoma de Honduras (National Autonomous University of Honduras); WHO: World Health Organization}

\section{Competing interests}

The authors declare that they have no competing interests.

\section{Authors' contributions}

ALS, TWG and MC conceived and designed the study; ALS, MC, MMR and JAG implemented the study; ALS, TWG and MC contributed reagents/ materials/analysis tools; JAG and ALS analyzed the data; JAG and ALS wrote the manuscript; TWG, MC, and MMR revised the manuscript and provided important intellectual content; ALS supervised the first author in all aspects of the study; all authors read and approved the final version of the manuscript.

\section{Acknowledgements}

Funding for the parent study was received from the Canadian Institutes for Health Research, CIHR (TWG, Principal Investigator). Additional funding was provided by a Teasdale-Corti grant from the Global Health Research Initiative, GHRI (ALS, Principal Investigator). Graduate research fellowships were awarded to JAG and MMR by Brock University and the Teasdale-Corti project, respectively.

We are grateful to the study communities, school Principals and teachers and research participants for their willingness and enthusiasm in participating in our study. We also wish to thank our colleagues at the UNA for their valuable collaboration. Field and laboratory work would have not been possible without the support of faculty and students of the School of Microbiology and the Masters Program in Infectious and Zoonotic Diseases at UNAH.

\section{Author details}

'Department of Health Sciences, Brock University, St. Catharines, Ontario, Canada. ${ }^{2}$ School of Microbiology, National Autonomous University of Honduras (UNAH), Tegucigalpa, Honduras. ${ }^{3}$ Microbiology Research Institute, UNAH, Tegucigalpa, Honduras. ${ }^{4}$ Division of Clinical Epidemiology, Research Institute of the McGill University Health Centre, Montreal, Quebec, Canada.

Received: 29 June 2014 Accepted: 29 July 2014

Published: 4 August 2014

\section{References}

1. Bethony J, Brooker S, Albonico M, Geiger SM, Loukas A, Diemert D, Hotez PJ: Soil-transmitted helminth infections: ascariasis, trichuriasis, and hookworm. Lancet 2006, 367(9521):1521-1532.

2. WHO: Prevention and Control of Schistosomiasis and Soil Transmitted Helminthiasis. Geneva, Switzerland: WHO Expert Committee; 2002.

3. Hotez PJ, Molyneux DH, Fenwick A, Kumaresan J, Sachs SE, Sachs JD, Savioli L: Control of neglected tropical diseases. N Engl J Med 2007, 357(10):1018-1027.

4. WHO: Accelerating Work to Overcome the Global Impact of Neglected Tropical Diseases: A Roadmap for Implementation: Executive Summary. Geneva: World Health Organization; 2012:42.

5. Hotez PJ: Forgotten People and Forgetten Diseases, the Neglected Tropical Diseases and Their Impact on Global Health and Development. Washington DC: American Society for Microbiology; 2008. 
6. Hall A, Hewitt $G$, Tuffrey $V$, de Silva N: A review and meta-analysis of the impact of intestinal worms on child growth and nutrition. Matern Child Nutr 2008, 4(Suppl 1):118-236.

7. Bisoffi Z, Buonfrate D, Montresor A, Requena Mendez A, Munoz J, Krolewiecki AJ, Gotuzzo E, Mena MA, Chiodini PL, Anselmi M, Moreira J, Albonico M: Strongyloides stercoralis: a plea for action. PLoS Negl Trop Dis 2013, 7:e2214

8. Krolewiecki AJ, Lammie P, Jacobson J, Gabrielli AF, Levecke B, Socias E, Arias LM, Sosa N, Abraham D, Cimino R, Echazu A, Crudo F, Vercruysse J, Albonico M: A public health response against Strongyloides stercoralis: time to look at soil-transmitted helminthiasis in full. PLoS Negl Trop Dis 2013, 7:e2165.

9. Schar F, Trostdorf U, Giardina F, Khieu V, Muth S, Marti H, Vounatsou P, Odermatt P: Strongyloides stercoralis: global distribution and risk factors. PLoS Negl Trop Dis 2013, 7(7):e2288.

10. WHO: Soil-Transmitted Helminthiases: Eliminating Soil-Transmitted Helminthiases as a Public Health Problem in Children. Progress Report 2001-2010 and Strategic Plan 2011-2020. Geneva: World Health Organization; 2012:79.

11. Lustigman S, Prichard RK, Gazzinelli A, Grant WN, Boatin BA, McCarthy JS, Basáñez M-G: A research agenda for helminth diseases of humans: the problem of helminthiases. PLoS Negl Trop Dis 2012, 6(4):e1582.

12. Weaver HJ, Hawdon JM, Hoberg EP: Soil-transmitted helminthiases: implications of climate change and human behavior. Trends Parasitol 2010, 26(12):574-581

13. Gazzinelli A, Correa-Oliveira R, Yang GJ, Boatin BA, Kloos H: A research agenda for helminth diseases of humans: social ecology, environmental determinants, and health systems. PLOS Negl Trop Dis 2012, 6(4):e1603.

14. Nishiura H, Imai H, Nakao H, RTsukino H, Changazi MA, Hussain GA, Kuroda Y, Katoh T: Ascaris lumbricoides among children in rural communities in the Northern Area, Pakistan: prevalence, intensity, and associated socio-cultural and behavioral risk factors. Acta Trop 2002, 83:223-231.

15. Pullan RL, Smith JL, Jasrasaria R, Brooker SJ: Global numbers of infection and disease burden of soil transmitted helminth infections in 2010. Parasit Vectors 2014, 7:37.

16. WHO: Soil-Transmitted Helminthiases: Number of Children Treated in 2010. In Weekly Epidemiological Record, vol. 87. Geneva: 2012:225-232.

17. Saboya MI, Catala L, Nicholls RS, Ault SK: Update on the mapping of prevalence and intensity of infection for soil-transmitted helminth infections in Latin America and the Caribbean: A call for action. PLoS Negl Trop Dis 2013, 7(9):e2419.

18. United Nations: Millennium Development Goals, Honduras 2010. Third country report. 2010.

19. Sanchez AL, Gabrie JA, Usuanlele MT, Rueda MM, Canales M, Gyorkos TW: Soil-transmitted helminth infections and nutritional status in school-age children from rural communities in Honduras. PLoS Negl Trop Dis 2013, 7(8):e2378.

20. Sanchez AL, Gabrie JA, Rueda MM, Mejia RE, Bottazzi ME, Canales M: A scoping review and prevalence analysis of soil-transmitted helminth infections in Honduras. PLoS Negl Trop Dis 2014, 8(1):e2653.

21. Katz N, Chaves A, Pellegrino J: A simple device for quantitative stool thick-smear technique in Schistosomiasis mansoni. Rev Inst Med Trop Sao Paulo 1972, 14(6):397-400.

22. WHO: Basic Laboratory Methods in Medical Parasitology. Geneva: World Health Organization; 1991.

23. Knopp S, Mgeni AF, Khamis IS, Steinmann P, Stothard JR, Rollinson D, Marti $H$, Utzinger J: Diagnosis of soil-transmitted helminths in the era of preventive chemotherapy: effect of multiple stool sampling and use of different diagnostic techniques. PLoS Negl Trop Dis 2008, 2(11):e331.

24. Raso G, Utzinger J, Silue KD, Ouattara M, Yapi A, Toty A, Matthys B, Vounatsou P, Tanner M, N'Goran EK: Disparities in parasitic infections, perceived ill health and access to health care among poorer and less poor schoolchildren of rural Cote d'Ivoire. Trop Med Int Health 2005, 10(1):42-57.

25. Gwatkin DR: Health inequalities and the health of the poor: what do we know? What can we do? Bull World Health Organ 2000, 78(1):3-18.

26. Steinmann $P$, Zhou X-N, Li Y-L, Li H-J, Chen S-R, Yang Z, Fan W, Jia T-W, Li L-H, Vounatsou P: Helminth infections and risk factor analysis among residents in Eryuan county, Yunnan province, China. Acta Trop 2007, 104(1):38-51.
27. PAHO: Epidemiological Profiles of Neglected Diseases and Other Infections Related to Poverty in Latin America and the Caribbean. Washington, DC: Pan American Health Organization; 2009.

28. Dold C, Holland CV: Ascaris and ascariasis. Microbes Infect 2011, 13(7):632-637.

29. Corrales LF, Izurieta R, Moe CL: Association between intestinal parasitic infections and type of sanitation system in rural El Salvador. Tropical Med Int Health 2006, 11(12):1821-1831.

30. Naish S, McCarthy J, Williams GM: Prevalence, intensity and risk factors for soil-transmitted helminth infection in a South Indian fishing village. Acta Trop 2004, 91(2):177-187.

31. Agudelo-Lopez S, Gómez-Rodríguez L, Coronado X, Orozco A, ValenciaGutierrez CA, Restrepo-Betancur LF, Galvis-Gómez LA, Botero-Palacio LE: [Prevalence of intestinal parasitism and associated factors in a village on the Colombian Atlantic Coast]. Revista Salud Pública 2008, 10(4):633-642.

32. Bundy DA, Cooper ES: Trichuris and trichuriasis in humans. Adv Parasitol 1989, 28:107-173.

33. Hotez PJ, Brooker S, Bethony JM, Bottazzi ME, Loukas A, Xiao S: Hookworm infection. N Engl J Med 2004, 351(8):799-807.

34. Alemayehu GS: Prevalence and Risk Factors of Soil-Transmitted Helminthes Among School Children in Abosa Around Lake Zway, Southern Ethiopia. MSc. Addis Ababa: Addis Ababa University; 2008.

35. Nelson KE, Masters CF: Infectious Diseases Epidemiology: Theory and Practice. 2nd edition. Mississauga: Jones and Bartlett; 2007.

36. Odiere MR, Opisa S, Odhiambo G, Jura WG, Ayisi JM, Karanja DM, Mwinzi PN: Geographical distribution of schistosomiasis and soil-transmitted helminths among school children in informal settlements in Kisumu City, Western Kenya. Parasitol 2011, 138(12):1569-1577.

37. Soares Magalhaes RJ, Barnett AG, Clements AC: Geographical analysis of the role of water supply and sanitation in the risk of helminth infections of children in West Africa. Proc Natl Acad Sci U S A 2011, 108(50):20084-20089.

38. Steenhard NR, Ornbjerg N, Molbak K: Concurrent infections and socioeconomic determinants of geohelminth infection: a community study of schoolchildren in periurban Guinea-Bissau. Trans $R$ Soc Trop Med Hyg 2009, 103(8):839-845.

39. Conlan JV, Khamlome B, Vongxay K, Elliot A, Pallant L, Sripa B, Blacksell SD, Fenwick S, Thompson RA: Soil-transmitted helminthiasis in Laos: a community-wide cross-sectional study of humans and dogs in a mass drug administration environment. Am J Trop Med Hyg 2012, 86(4):624-634.

40. Gunawardena K, Kumarendran B, Ebenezer R, Gunasingha MS, Pathmeswaran A, de Silva N: Soil-transmitted helminth infections among plantation sector schoolchildren in Sri Lanka: prevalence after ten years of preventive chemotherapy. PLoS Negl Trop Dis 2011, 5(9):e1341.

41. Hohmann H, Panzer S, Phimpachan C, Southivong C, Schelp FP: Relationship of intestinal parasites to the environment and to behavioral factors in children in the Bolikhamxay Province of Lao PDR. Southeast Asian J Trop Med Public Health 2001, 32:4-13.

42. Lello J, Knopp S, Mohammed KA, Khamis IS, Utzinger J, Viney ME: The relative contribution of co-infection to focal infection risk in children. Proc Biol Sci 2013, 280(1754):20122813.

43. Coulibaly JT, Furst T, Silue KD, Knopp S, Hauri D, Ouattara M, Utzinger J, N'Goran EK: Intestinal parasitic infections in schoolchildren in different settings of Cote d'Ivoire: effect of diagnostic approach and implications for control. Parasit Vectors 2012, 5:135.

44. Bundy D: Gender-dependent patterns of infections and disease. Parasitol Today (Personal ed) 1988, 4(7):186.

45. Poulin R: Sexual inequalities in helminth infections: a cost of being a male? Am Nat 1996, 147(2):287-295.

46. Zuk M, McKean KA: Sex differences in parasite infections: patterns and processes. Int J Parasitol 1996, 26(10):1009-1024.

47. Brooker S, Bethony J, Hotez PJ: Human hookworm infection in the 21st century. Adv Parasitol 2004, 58:197-288.

48. Cairncross S, Blumenthal U, Kolsky P, Moraes L, Tayeh A: The public and domestic domains in the transmission of disease. Trop Med Int Health 1996, 1(1):27-34.

49. Olsen A, Samuelsen $H$, Onyango-Ouma W: A study of risk factors for intestinal helminth infections using epidemiological and anthropological approaches. J Biosoc SCi 2001, 33(4):569-584.

50. Balen J, Raso G, Li YS, Zhao ZY, Yuan LP, Williams GM, Luo XS, Shi MZ, Yu $X \mathrm{~L}$, Utzinger J, McManus DP: Risk factors for helminth infections in a rural 
and a peri-urban setting of the Dongting Lake area, People's Republic of China. Int J Parasitol 2011, 41:1165-1173.

51. Halpenny CM, Paller C, Koski KG, Valdés VE, Scott ME: Regional, household and individual factors that influence soil transmitted helminth reinfection dynamics in preschool children from rural indigenous Panamá. PLoS Negl Trop Dis 2013, 7(2):e2070.

52. Kounnavong $S$, Vonglokham M, Houamboun $K$, Odermatt P, Boupha B: Soil-transmitted helminth infections and risk factors in preschool children in southern rural Lao People's Democratic Republic. Trans R Soc Trop Med Hyg 2011, 105(3):160-166

53. Sayasone S, Mak TK, Vanmany M, Rasphone O, Vounatsou P, Utzinger J, Akkhavong K, Odermatt P: Helminth and intestinal protozoa infections, multiparasitism and risk factors in Champasack province, Lao People's Democratic Republic. PLoS Negl Trop Dis 2011, 5(4):e1037.

54. Roberts LS, Janovy J: N: Strongyloidea, Bursate Rhabditidans. In Gerald D Schmidt \& Larry S Roberts' Foundations of Parasitology/Larry S Roberts, John Janow, Jr, Volume c2009. 8th edition. Edited by Reidy PE. New York, NY: McGraw Hill; 2009.

55. Gamboa MI: [Intestinal parasites and poverty: the vulnerability of the poorest people in Argentina in a globalized World]. I Selva Andina Res Soc 2011, 1(1):1.

56. Gamboa MI, Kozubsky LE, Costas ME, Garraza M, Cardozo MI, Susevich ML, Magistrello PN, Navone GT: [Associations between geohelminths and socioenvironmental conditions among different human populations in Argentina]. Revista Panamericana de Salud Pública 2009, 26(1):1-8.

57. Hesham Al-Mekhlafi M, Surin J, Atiya AS, Ariffin WA, Mohammed Mahdy AK, Che Abdullah H: Pattern and predictors of soil-transmitted helminth reinfection among aboriginal schoolchildren in rural Peninsular Malaysia. Acta Trop 2008, 107(2):200-204

58. Scolari C, Torti C, Beltrame A, Matteelli A, Castelli F, Gulletta M, Ribas M, Morana S, Urbani C: Prevalence and distribution of soil-transmitted helminth (STH) infections in urban and indigenous schoolchildren in Ortigueira, State of Parana, Brasil: implications for control. Trop Med Int Health 2000, 5(4):302-307.

59. WHO: WHO Guidelines on Hand Hygiene in Health Care. Geneva, Switzerland: World Health Organization; 2009:262.

60. Bartram J, Cairncross S: Hygiene, sanitation, and water: forgotten foundations of health. PLOS Med 2010, 7(11):e1000367.

61. Stauber CE, Walters A, de Aceituno AM F, Sobsey MD: Bacterial contamination on household toys and association with water, sanitation and hygiene conditions in Honduras. Int J Environ Res Public Health 2013, 10(4):1586-1597.

62. Alemu A, Atnafu A, Addis Z, Shiferaw Y, Teklu T, Mathewos B, Birhan W, Gebretsadik S, Gelaw B: Soil transmitted helminths and Schistosoma mansoni infections among school children in Zarima town, northwest Ethiopia. BMC Infect Dis 2011, 11:189.

63. Fung IC, Cairncross S: Ascariasis and handwashing. Trans R Soc Trop Med Hyg 2009, 103(3):215-222.

64. Biran A, Rabie T, Schmidt W, Juvekar S, Hirve S, Curtis V: Comparing the performance of indicators of hand-washing practices in rural Indian households. Trop Med Int Health 2008, 13(2):278-285.

65. Díaz M, Moncada L, Reyes P, Fernández J, Cano D, Suárez R: [Knowledge, attitudes and practices about geohelminths in a rural community of Colombia]. Revista Med 2010, 8(1):18-28.

66. Keiser J, Utzinger J: Efficacy of current drugs against soil-transmitted helminth infections: systematic review and meta-analysis. JAMA 2008, 299(16):1937-1948.

67. Vercruysse J, Behnke JM, Albonico M, Ame SM, Angebault C, Bethony JM, Engels D, Guillard B, Nguyen TV, Kang G, Kattula D, Kotze AC, McCarthy JS, Mekonnen Z, Montresor A, Periago MV, Sumo L, Tchuente LA, Dang TC, Zeynudin A, Levecke B: Assessment of the anthelmintic efficacy of albendazole in school children in seven countries where soil-transmitted helminths are endemic. PLoS Negl Trop Dis 2011, 5:e948.

68. Kamga HLF, Nsagha DS, Atanga MBS, Njunda AL, Assob JCN, Fon PN, Fomumbod SA: The impact of health education on the prevalence of faecal-orally transmitted parasitic infections among school children in a rural community in Cameroon. Pan Afr Med J 2011, 8:1-8.

69. WHO: Helminth Control in School age Children: A Guide for Managers of Control Programmes. 2nd edition. Geneva: World Health Organization; 2011:90.

70. WHO: Working to Overcome the Global Impact of Neglected Tropical Diseases France: World Health Organization; 2010:172.

71. Anantaphruti M, Waikagul J, Maipanich W, Nuamtanong S, Watthanakulpanich D, Pubampen S, Kusolsuk T: School-based health education for the control of soil-transmitted helminthiases in Kanchanaburi province, Thailand. Ann Trop Med Parasitol 2008, 102(6):521-528.

72. Nasr NA, Al-Mekhlafi HM, Ahmed A, Roslan MA, Bulgiba A: Towards an effective control programme of soil-transmitted helminth infections among Orang Asli in rural Malaysia. Part 2: Knowledge, attitude, and practices. Parasit Vectors 2013, 6:28.

73. Campbell SJ, Savage GB, Gray DJ, Atkinson JA, Soares Magalhaes RJ, Nery SV, McCarthy JS, Velleman Y, Wicken JH, Traub RJ, Williams GM, Andrews RM, Clements AC: Water, sanitation, and hygiene (WASH): a critical component for sustainable soil-transmitted helminth and schistosomiasis control. PLoS Negl Trop Dis 2014, 8:e2651.

74. Freeman MC, Ogden S, Jacobson J, Abbott D, Addiss DG, Amnie AG, Beckwith C, Cairncross S, Callejas R, Colford JM Jr: Integration of water, sanitation, and hygiene for the prevention and control of neglected tropical diseases: a rationale for inter-sectoral collaboration. PLOS Negl Trop Dis 2013, 7(9):e2439.

75. Strunz EC, Addiss DG, Stocks ME, Ogden S, Utzinger J, Freeman MC: Water, sanitation, hygiene, and soil-transmitted helminth infection: a systematic review and meta-analysis. PLoS Med 2014, 11(3):e1001620.

76. Ulukanligil M, Seyrek A: Demographic and parasitic infection status of schoolchildren and sanitary conditions of schools in Sanliurfa, Turkey. BMC Public Health 2003, 3:29.

77. Freeman MC, Clasen T, Brooker SJ, Akoko DO, Rheingans R: The impact of a school-based hygiene, water quality and sanitation intervention on soil-transmitted helminth reinfection: a cluster-randomized trial. Am J Trop Med Hyg 2013, 89(5):875-883.

78. Brooker S, Clements AC, Bundy DA: Global epidemiology, ecology and control of soil-transmitted helminth infections. Adv Parasitol 2006, 62:221-261.

79. Bogitsh BJ, Carter CE, Oeltmann TN: Human Parasitology. Fourth edition. Waltham, MA, USA: Elsevier Academic Press; 2012.

80. Albonico M, Engels D, Savioli L: Monitoring drug efficacy and early detection of drug resistance in human soil-transmitted nematodes: a pressing public health agenda for helminth control. Int J Parasitol 2004, 34(11):1205-1210.

81. WHO: Preventive Chemotherapy in Human Helminthiasis. Coordinated use of Anthelminthic Drugs in Control Interventions: A Manual for Health Professionals and Programme Managers. France: World Health Organization; 2006:62.

82. Hollingsworth TD, Truscott JE, Anderson RM: Transmission Dynamics of Ascaris Lumbricoides - Theory and Observation. In Ascaris The Neglected Parasite. Edited by Holland C. London, UK: Academic Press; 2013:231-262.

83. Truscott JE, Hollingsworth TD, Brooker SJ, Anderson RM: Can chemotherapy alone eliminate the transmission of soil transmitted helminths? Parasites Vectors 2014, 7(1):266

84. Montressor A, Gabrielly AF, Savioli L: Approaches to Control of STHs Including Ascariasis. In Ascaris: The Neglected Parasite Newnes, 2013. Edited by Holland C. London, UK: Academic Press; 2013:383-393.

85. Adams VJ, Lombard CJ, Dhansay MA, Markus MB, Fincham JE: Efficacy of albendazole against the whipworm Trichuris trichiura -a randomised, controlled trial. S Afr Med J 2004, 94(12):972-976.

86. Macnab AJ, Gagnon FA, Stewart D: Health promoting schools: consensus, strategies, and potential. Health Educ 2014, 114(3):1-1.

87. Honduras Ministry of Health: Strategic Plan for the Prevention, Attention, Control, and Elimination of Neglected Infectious Diseases in Honduras (PEEDH). 2012-2017. Tegucigalpa: M.D.C. Honduras: Honduras Ministry of Health; 2012:1-31.

88. Buonfrate D, Mena MA, Angheben A, Requena-Mendez A, Munoz J, Gobbi F, Albonico M, Gotuzzo E, Bisoffi Z: Prevalence of strongyloidiasis in Latin America: a systematic review of the literature. Epidemiol Infect 2014, July:1-9.

89. Dacombe RJ, Crampin AC, Floyd S, Randall A, Ndhlovu R, Bickle Q, Fine PE: Time delays between patient and laboratory selectively affect accuracy of helminth diagnosis. Trans R Soc Trop Med Hyg 2007, 101(2):140-145.

90. Honduras Ministry of Health: Prevalence of Soil-Transmitted Helminthiases and Malaria in School Children. Characterization of Socio-Cultural and Environmental Risk Factors. 2011. Tegucigalpa: M.D.C. Honduras: Honduras Ministry of Health; 2011:1-179.

91. Krauth SJ, Coulibaly JT, Knopp S, Traoré M, N'Goran EK, Utzinger J: An in-depth analysis of a piece of shit: distribution of Schistosoma mansoni and hookworm eggs in human stool. PLoS Negl Trop Dis 2012, 6(12):e1969.

92. Tarafder MR, Carabin H, Joseph L, Balolong E Jr, Olveda R, McGarvey ST: Estimating the sensitivity and specificity of Kato-Katz stool examination 
technique for detection of hookworms, Ascaris lumbricoides and Trichuris trichiura infections in humans in the absence of a 'gold standard'. Int J Parasitol 2010, 40(4):399-404.

93. Barda B, Zepherine H, Rinaldi L, Cringoli G, Burioni R, Clementi M, Albonico M: Mini-FLOTAC and Kato-Katz: helminth eggs watching on the shore of Lake Victoria. Parasit Vectors 2013, 6(1):220.

94. Kabatereine NB, Malecela M, Lado M, Zaramba S, Amiel O, Kolaczinski JH: How to (or not to) integrate vertical programmes for the control of major neglected tropical diseases in sub-Saharan Africa. PLoS Negl Trop Dis 2010, 4(6):e755.

95. Knopp S, Stothard JR, Rollinson D, Mohammed KA, Khamis IS, Marti H, Utzinger J: From morbidity control to transmission control: time to change tactics against helminths on Unguja Island, Zanzibar. Acta Trop 2011, 128:412-422.

doi:10.1186/1756-3305-7-354

Cite this article as: Gabrie et al.: School hygiene and deworming are key protective factors for reduced transmission of soil-transmitted helminths among schoolchildren in Honduras. Parasites \& Vectors

2014 7:354

\section{Submit your next manuscript to BioMed Central and take full advantage of:}

- Convenient online submission

- Thorough peer review

- No space constraints or color figure charges

- Immediate publication on acceptance

- Inclusion in PubMed, CAS, Scopus and Google Scholar

- Research which is freely available for redistribution 